\title{
Depression Level and Burden of Care Among Family Caregivers of Older People With Physical and Mental Disability in Makkah City KSA
}

\author{
Haitham Al-shareef ${ }^{1}$, Abd Alhadi Hasan ${ }^{2} \&$ Hussein Tumah ${ }^{3}$ \\ ${ }^{1}$ Clinical Nurse Manager, Home Care, Mekkah, Saudi Arabia \\ ${ }^{2}$ Assistant Professor in Mental Health Nursing, Nursing Department, Fakeeh College for Medical Sciences, \\ Jeddah, Saudi Arabia \\ ${ }^{3}$ Assistant Professor in Nursing Education, Fakeeh College for Medical Sciences, Jeddah, Saudi Arabia \\ Correspondence: Abd Alhadi Hasan, Assistant Professor in Mental Health Nursing, Nursing Department, Fakeeh \\ College for Medical Sciences, Alhamra District, Jeddah, Saudi Arabia. Tel: 966-53-640-6602; Fax: \\ 966-54-7654-3216. E-mail: aalhasan@fakeeh.care
}

Received: February 18, 2019 Accepted: March 18, 2019 Online Published: April 3, 2019

doi:10.5539/gjhs.v11n5p41 URL: https://doi.org/10.5539/gjhs.v11n5p41

\begin{abstract}
Aims: This study is aimed at examining the burden of care and depression level among the family caregivers of client diagnosed with physical or mental disability. In addition, this study purposed to test the relationship between socio-demographic factors and level of depression and burden of care.

Methods: Study design was a descriptive survey design. Study sample was 129 family caregivers of patients diagnosed with physical and mental disabilities in Makkah, Kingdom of Saudi Arabia. Data collected using a pre-designed structured interviewing questionnaire including the Beck Depression Inventory scale (Beck, Steer, \& Brown, 1996) and Family Burden Interview Schedule.

Results: Percentage of depression level ranged from $63 \%$ among caregivers of physically disorder clients to $69 \%$ among caregivers of mentally disorder clients. Moreover, there were many factors that may increase risk of depression such as old age of caregivers, spouse and caregivers who cared for their charges four hours or more per day. There was significant difference in depression level and burden of care as regard to nature of relative illness ( $p$ $<0.05$ ).
\end{abstract}

Conclusions: Policies and programs to alleviate the burden of care and to provide social support for these family caregivers are equally important for both family caregivers and their care receivers.

Keywords: depression, burden of care, older people, home care

\section{Background}

There is an increase in the numbers of older people. People worldwide and it is estimated that the proportion of the world's older adults will reach $22 \%$ in 2050 . Older people individuals are at risk of developing mental disorders, neurological disorders or substance abuse problems as well as other health conditions such as diabetes, hearing loss, and osteoarthritis. Furthermore, some of older people may experience co-morbidity, being diagnosed with several diseases at the same time (WHO, 2016). As a result, older people frequently need support in daily life activities and/or help from others to cope with disabilities and make their life easier to perform activity of daily living (Mosqueda et al., 2004).

Few studies have examined the factors associated with depression among caregivers. Pirraglia et al. (2005), conducted a study to explore the relationship between depression and burden of care among informal caregivers of HIV-infected persons. Study design was cross-sectional; the study sample was 176 of HIV patients and their informal caregiver. A scale of 21-questions called Beck Depression Inventory (BDI) was used to measure caregiver's depression while the caregiver's burden was assessed using the Caregiver Strain Index (CSI). The study revealed that median age of caregivers was 42 years, $53 \%$ were females, $30 \%$ had an educational degree beyond high school, $47 \%$ were the patient's partner, friends were $18 \%$ and $35 \%$ were a family member. Caregivers who had a high caregiver burden were $27 \%$, and $50 \%$ of them were depressed. In addition, $25 \%$ of informal caregivers 
were themselves having HIV positive. Results revealed that the burden of caregiving was strongly and independently associated with depression in the informal caregiver of HIV-infected individuals. In addition, medical comorbidity besides HIV in the informal caregiver, illicit drug use by the informal caregiver, having others to help besides the HIV patient, spending all day together, and duration of the HIV patient's diagnosis were also associated with greater depression in the informal caregiver. Of all other characteristics of the informal caregiver, of the relationship between the informal caregiver and HIV patient, or of the HIV patient, none was independently associated with depression in the informal caregiver.

The study recommends the need for additional research to determine effective means to support caregivers and the older patients with depression and to identify their problems, which has significant implications not only for the health and well-being of caregivers but also for their ability to provide effective care for a susceptible group of older adults. Masakazu et al., (2014) investigated the factors led to depression among family caregivers of older people with physical disabilities who used Home Health Care in the Metropolitan City of Hokkaido, Northern Japan. The design was a cross sectional, using a self-administered questionnaire, including the Center for Epidemiologic Studies Depression Scale (CES-D) to evaluate the participant depression. The study showed that $45.5 \%$ of caregivers were depressed and the finding also revealed that there were many factors that may increase risk of depression such as old age of caregivers, spouse, caregivers who cared for their charges four hours or more per day and caregivers having chronic disease. The study recommends that care should be directed to family caregivers especially spouse or older caregivers in addition to the care given to disabled older people.

A study conducted by (Toyoshima et al., 2014), aimed to evaluate the burden and depression among 78 pairs of psychiatric clients who were receiving services of nursing home visits and their caregivers. A cross sectional design was used to investigate the caregivers and their clients who were having psychiatric problems. The used questionnaire included self-administered Japanese version of Zarit Caregiver Burden Interview (ZBI) and a Japanese version of the Center for Epidemiologic Studies Depression (CES-D) Scale. The results showed that $(50 \%)$ of caregivers were depressed and (57.7\%) clients were diagnosed with schizophrenia. The results also revealed that depressed caregivers attend hospitals for treatment for their own chronic diseases and were significantly burdened. The study also mentioned that physically disabled clients might need physical care only while psychiatric clients needed both (physical and psychiatric care). In a study conducted by (washio, et al., 2015) in Japan to investigate factors that lead to depression among caregivers of frail clients who were using visiting nursing services, sample was 68 pairs of caregivers and their clients, and the design of the study was cross sectional. The questionnaire was used for measuring the burden of caregivers. Mental disability defines as any form of mental illness according to DSM-V and physical disability includes any form of somatic disorder, mainly neurological and cardiac problems (Khan et al., 2016).

The result revealed that $43.3 \%$ of the caregivers were depressed and significantly burdened and using public services more than non-depressed caregivers. Results also revealed that there were many factors that may increase risk of depression such as old age of caregivers or being a spouse. The study also showed a heavy burden among caregivers when spending more time with the clients; it is considered additional risk factor for them

Khan et al. (2016) conducted a study to examine burden and depression among caregivers of visually impaired patients in a Canadian population. It was a clinic-based, cross-sectional survey in a tertiary care hospital. Caregivers were considered unpaid family members for patients whose sole impairment was visual. Patients were stratified by vision in their better seeing eye into two groups: Group 1 had visual acuity between 6/18 and 6/60 and Group 2 were those who had 6/60 or worse. Burden was evaluated by the Burden Index of Caregivers and the prevalence of being at risk for depression was determined by the Center for Epidemiologic Studies Depression scale. Results revealed that total mean Burden Index of Caregivers scores were higher in Group 2. Female caregivers, caregivers providing greater hours of care, and caregivers of patients who have not completed vision rehabilitation programs were at higher risk for depression. The aim of the study was to assess the burden of care and level of depression among the family caregivers of older people patients. This study added to understand the Saudi caregivers psychosocial problems as a result of providing direct care for ill relatives.

\section{Methods}

\subsection{Design}

The study was employed descriptive survey design.

\subsection{Study Setting \& Recruitment}

In the Kingdom of Saudi Arabia there are 209 hospitals implement the services of "Home Health Care". The number of service users are 27764 patients. In Makah where the study was conducted, there are 7 hospitals provide 
home health care services to, 1749 patients. (Statistics from the home health care program administration, department of statistics, till the end of April 2017).

\subsection{Sampling}

\subsubsection{Participants}

\section{Inclusion Criteria}

Caregivers had to be free from any mental illness, they had to consent voluntarily to participate in the study and they had to be willing to participate. Caregivers needed to be able to read and understand either Arabic or English.

\section{Sample Size}

The target sample of this study was 300 family caregivers and the final sample consisted of 129 family caregivers (response rate $43 \%$ ) of patients diagnosed with physical and psychiatric problems. The sample size was calculated based on power $80 \%$, level of significance 0.05 , then the required sample size is 270 with attrition rate $15 \%$.

\section{Data Collection Procedure}

Ethical approval was obtained from the Institutional Review Board (IRB) committee in the Ministry of Health. Following the explanation phase of the initial approach, eligible potential participants were given written information about the study, including the electronic information sheet along with relevant consent forms that they could take home prior to deciding whether to participate in the study. These electronic information sheets were supported by text message explanation about the study's importance and the proposed effect on their life. They were told they had the freedom to withdraw from the study at any time without explanation.

\section{Data Collection Method and Outcomes Measure}

A pre-designed structured interviewing questionnaire including the following items:

Personal data: Age, sex, residence, marital status, level of education, economic status, occupation, relation of the caregiver to the patient, number of contact hours spent with the patient and duration of caring process.

Determination of the severity of depression symptoms among caregivers using Beck Depression Inventory scale. This scale was devised by Beck, Steer, and Brown (1996) and was used to assess the severity of affective, behavioral, cognitive and somatic symptoms of depression. It includes statements that cover items related to the basic symptoms of depression, such as hopelessness and irritability, feeling of guilt or feelings of being punished, as well as physical symptoms such as fatigue, weight loss, and lack of interest in sex. The translated version showed excellent reliability, Cronbach's Alpha coefficient of the scale as a whole amounted to (0.807), which is an acceptable reliability coefficient since it exceeds (0.70) as stated by (Malkawi and Odeh, 2014).

This scale consists of 21 -items, each answer of the participants was scored on a Likert type scale ranging from 0 to 3 , the highest score indicates that individual's experience of severe episode of depression.

Measurement of the burden of care among caregivers using the family burden interview schedule (FBIS). This scale was devised by Pai and Kapur (1981). The FBIS has 24 items and focuses on six domains of primary caregivers' burden: family finance, routine, leisure time, physical health, mental health and family interaction. Each item is rated on a three-point Likert scale ( 0 : no burden, 1: moderate burden, 2: severe burden) scored from 0 to 48; a higher score indicates a higher level of burden. The scale has a (Cronbach's alpha of 0.87) and test-retest reliability of 0.83 . The translated version showed excellent reliability (Cronbach's alpha, 0.86) and inter-rater reliability (ICC, 0.86).

\subsection{Ethical Approval}

Ethical approval was obtained from the Institutional Review Board (IRB) committee in the Ministry of Health. All participants were informed and a written consent was taken from every participant after explaining the aim of the study. No obligation of any kind for participating in the study, and every participant was free to withdraw from completing the study at any time.

\subsection{Data Analysis}

Data entry and statistical analysis were done by using the Statistical Package for the Social Sciences (SPSS) version 23. Statistical significance was set at $p<0.05$. Descriptive and inferential statistical techniques were utilized to analyze the collected data. These techniques included (frequencies, percentages, mean value and standard deviations). In addition to Chi Square Test applied to examine differences among groups for most of the variables such as age, gender, marital status or level of education. 


\section{Results}

\subsection{Sociodemographic Characteristics of the Study Participants}

Approximately 300 of electronic questionnaires were distributed, a Google Play link (Google Play link was used to prepare the questionnaire). The total number of returned questionnaire was 129 (response rate is $43 \%$ ).

Tables 1 and 2 summarize the sociodemographic characteristics of the study participants. The majority (47.3\%) of the participants' age ranged from $31-40$ years $(17.1 \%$ caring for mentally disabled and $30.2 \%$ caring for physically disabled). In addition, the majority of the family caregivers were female in both groups. Over half of those who were caring for physically or mentally disabled were married, more than half $(67 \%)$ were holding bachelor degree. In terms of economic status, most of the study participants had a monthly income of less than 9000 SR. Most of the family caregivers were son and daughter. Most of them caring for their relative more than one year they formed $35.7 \%$ and had more four contact hours daily.

Table 1. Sociodemographic Characteristics of the study participants

\begin{tabular}{|c|c|c|c|c|c|c|}
\hline & \multicolumn{2}{|c|}{ Mental disability } & \multicolumn{2}{|c|}{ Physical disability } & \multirow{2}{*}{ Total } & \multirow{2}{*}{ P value } \\
\hline & Frequency & $\%$ & Frequency & $\%$ & & \\
\hline \multicolumn{7}{|l|}{ Family Caregivers } \\
\hline \multicolumn{7}{|l|}{ Gender of caregiver } \\
\hline Male & 24 & $18.6 \%$ & 36 & $27.9 \%$ & 60 & \multirow[t]{3}{*}{0.92} \\
\hline Female & 27 & $20.9 \%$ & 42 & $32.6 \%$ & 69 & \\
\hline Total & 51 & $39.5 \%$ & 78 & $60.5 \%$ & 129 & \\
\hline \multicolumn{7}{|l|}{ Age } \\
\hline 20 or less & 0 & $0 \%$ & 1 & $0.8 \%$ & 1 & \multirow{6}{*}{0.29} \\
\hline 21-30 & 10 & $7.8 \%$ & 15 & $11.6 \%$ & 25 & \\
\hline $31-40$ & 22 & $17.1 \%$ & 39 & $30.2 \%$ & 61 & \\
\hline $41-50$ & 13 & $10.1 \%$ & 19 & $14.7 \%$ & 32 & \\
\hline$>\mathbf{5 0}$ & 6 & $4.7 \%$ & 4 & $3.1 \%$ & 10 & \\
\hline Total & 51 & $39.5 \%$ & 78 & $60.5 \%$ & 129 & \\
\hline \multicolumn{7}{|l|}{ Social status } \\
\hline Single & 11 & $8.5 \%$ & 20 & $15.5 \%$ & 31 & \multirow{5}{*}{0.92} \\
\hline Married & 32 & $24.8 \%$ & 44 & $34.1 \%$ & 76 & \\
\hline Divorced & 7 & $5.4 \%$ & 12 & $9.3 \%$ & 19 & \\
\hline Widow & 1 & $0.8 \%$ & 2 & $1.6 \%$ & 3 & \\
\hline Total & 51 & $39.5 \%$ & 78 & $60.5 \%$ & 129 & \\
\hline \multicolumn{7}{|l|}{ Educational status } \\
\hline Can read and write & 0 & $0 \%$ & 1 & $0.8 \%$ & 1 & \multirow{7}{*}{0.59} \\
\hline Primary level & 0 & $0 \%$ & 3 & $2.3 \%$ & 3 & \\
\hline Secondary level & 1 & $0.8 \%$ & 2 & $1.65 \%$ & 3 & \\
\hline High school level & 16 & $12.4 \%$ & 17 & $13.2 \%$ & 33 & \\
\hline University level & 34 & $26.4 \%$ & 54 & $41.9 \%$ & 88 & \\
\hline Postgraduate & 0 & $0 \%$ & 1 & $0.8 \%$ & 1 & \\
\hline Total & 51 & $39.5 \%$ & 78 & $60.5 \%$ & 129 & \\
\hline
\end{tabular}




\begin{tabular}{|c|c|c|c|c|c|c|}
\hline \multicolumn{6}{|l|}{ Economic status } & \multirow{6}{*}{0.83} \\
\hline Less than $3000 \mathrm{SR}$ & 6 & $4.7 \%$ & 13 & $10.1 \%$ & 19 & \\
\hline 3000 - Less than 6000 SR & 13 & $10.1 \%$ & 16 & $12.4 \%$ & 29 & \\
\hline 6000 - Less than 9000 SR & 20 & $15.5 \%$ & 30 & $23.3 \%$ & 50 & \\
\hline 9000 SR or more & 12 & $9.3 \%$ & 19 & $14.7 \%$ & 31 & \\
\hline Total & 51 & $39.5 \%$ & 78 & $60.5 \%$ & 129 & \\
\hline \multicolumn{6}{|l|}{ Relationship to patient } & \multirow{6}{*}{0.97} \\
\hline Parent & 4 & $3.1 \%$ & 8 & $6.2 \%$ & 12 & \\
\hline Spouse & 6 & $4.7 \%$ & 6 & $4.7 \%$ & 12 & \\
\hline Patients brother and sister & 7 & $5.4 \%$ & 11 & $8.5 \%$ & 18 & \\
\hline Offspring & 34 & $26.4 \%$ & 53 & $41.1 \%$ & 87 & \\
\hline Total & 51 & $39.5 \%$ & 78 & $60.5 \%$ & 129 & \\
\hline \multicolumn{6}{|c|}{ The number of hours spent with the patient per day } & \multirow{4}{*}{0.96} \\
\hline Less than four hours & 42 & $32.6 \%$ & 64 & $49.6 \%$ & 106 & \\
\hline Four hours or more & 9 & $7.0 \%$ & 14 & $10.9 \%$ & 23 & \\
\hline Total & 51 & $39.5 \%$ & 78 & $60.5 \%$ & 129 & \\
\hline \multicolumn{6}{|l|}{ How long have you been caring? } & \multirow{5}{*}{0.37} \\
\hline Less than 6 months & 11 & $8.5 \%$ & 12 & $9.3 \%$ & 23 & \\
\hline 6 months or more & 40 & $31.0 \%$ & 66 & $51.2 \%$ & 106 & \\
\hline Total & 51 & $39.5 \%$ & 78 & $60.5 \%$ & 129 & \\
\hline Are you a primary caregiver? & $39.5 \%$ & & $60.5 \%$ & & $100 \%$ & \\
\hline \multicolumn{7}{|c|}{ Are you occupied with other issues? } \\
\hline No & 11 & $8.5 \%$ & 19 & $14.7 \%$ & 30 & \multirow{3}{*}{0.71} \\
\hline Yes & 40 & $31.0 \%$ & 59 & $45.7 \%$ & 99 & \\
\hline Total & 51 & $39.5 \%$ & 78 & $60.5 \%$ & 129 & \\
\hline \multicolumn{7}{|l|}{ Gender of Patients } \\
\hline Male & 33 & $25.6 \%$ & 56 & $43.4 \%$ & 89 & \multirow{3}{*}{0.39} \\
\hline Female & 18 & $14.0 \%$ & 22 & $17.1 \%$ & 40 & \\
\hline Total & 51 & $39.5 \%$ & 78 & $60.5 \%$ & 129 & \\
\hline \multicolumn{6}{|l|}{ Age of Patients } & \multirow{7}{*}{0.96} \\
\hline$\leq \mathbf{2 0}$ & 1 & $0.8 \%$ & 3 & $2.3 \%$ & 4 & \\
\hline 21 and 30 & 1 & $0.8 \%$ & 4 & $3.1 \%$ & 5 & \\
\hline 31 and 40 & 5 & $3.9 \%$ & 2 & $1.6 \%$ & 7 & \\
\hline 41 and 50 & 5 & $3.9 \%$ & 5 & $3.9 \%$ & 10 & \\
\hline$>50$ & 39 & $30.2 \%$ & 64 & $49.6 \%$ & 103 & \\
\hline Total & 51 & $39.5 \%$ & 78 & $60.5 \%$ & 129 & \\
\hline
\end{tabular}

The mean score of depression among caregivers of clients diagnosed with mental disability was higher than caregivers of clients diagnosed with physical disability (17.43 and 17.03 respectively), as indicated in Table 3 . Independent sample t-test was used to compare the depression score between family caregivers of clients diagnosed with mental or physical disability. There was no significant difference in depression level as regard to nature of relative illness $(\mathrm{p}<0.05)$. 
Table 3. Depression Scores amongst the caregivers

\begin{tabular}{llllll}
\hline & Type of Patients disability & N & Mean & Std. Deviation & P value \\
\hline \multirow{2}{*}{ Depression Score } & Mental disability & 51 & 17.43 & 10.743 & 0.84 \\
\cline { 2 - 5 } & Physical disability & 78 & 17.03 & 12.360 & \\
\hline
\end{tabular}

The mean score of depression among caregivers of clients diagnosed with mental disability was higher than caregivers of clients diagnosed with physical disability (18.62 and 13.84 respectively), as indicated in Table 4 . Independent sample t-test was used to compare the depression score between family caregivers of clients diagnosed with mental or physical disability. There was no significant difference in depression level as regard to nature of relative illness $(\mathrm{p}<0.05)$.

Table 4. Burden of Care Scores amongst the caregivers

\begin{tabular}{llllll}
\hline & Type of Clients disability & N & Mean & Std. Deviation & P value \\
\hline \multirow{2}{*}{ Burden of care score } & Mental disability & 51 & 18.6275 & 11.05796 \\
\cline { 2 - 5 } & Physical disability & 78 & 13.8462 & 7.60884 & 0.03 \\
\hline
\end{tabular}

\section{Discussion}

Caring of elder people with disabilities is often associated with mentally and physically burdened of caregiver (Maeda, 2003). The psychological health of the family caregiver is negatively affected by providing care to elder people with disabilities. Higher levels of depressive symptoms and mental health problems among caregivers than among their non-caregiving peers (Pinquart et al., 2003).

The result of the study showed that percentage of depression ranged from $63 \%$ among caregivers of physically disorder clients to $69 \%$ among caregivers of mental disorder clients. This finding agreed with (National Alliance for Caregiving [NAC], 2008, 2009) which stated that between 40 and $70 \%$ of caregivers have clinically significant symptoms of depression, with approximately one quarter to one half of these caregivers meeting the diagnostic criteria for major depression.

On the other hand, level of depression among caregivers in the present study was higher than the previous studies of (Washio et al., 2003; Oura et al., 2007; Hashimoto et al., 2013; Washio et al., 2014; Masakazu et al., 2014) and (Pirraglia et.al 2005) who stated that percentage of depression among caregivers ranged from $(43 \%-50 \%)$. This result can be explained that the caregivers in the present study were married $(54.8 \%)$ with multiple social responsibilities, university students (31\%) and offspring (12\%) forming large sector of the sample. Moreover, percentage of caregivers in the present study who were caring their clients for a period of six months or more was $(76.2 \%)$ and those who were occupied with other issues were $(79.8 \%)$. These factors leaded to higher percentage of depression among caregivers in the present study than the previous studies.

In the current study, level of depression among caregivers was higher in females than males. Moreover, level of depression was higher among caregivers $>50$ years old, and among caregivers with spousal relationship with the disabled client. These findings were in agreed with (Mc Grath et al., 2002; Vitaliano et al., 2003; Masakazu et al., 2014; Khan et al., 2016; Pinquart, 2003) who stated that greater degrees of depression and low ratings of subjective well-being among caregivers are consistently associated with old age of caregiving, a spouse relationship with the clients and being a female who have higher rates of depression than men in the care-giving role.

However, a study by Khare et al., (2016) stated that aunts, nieces, and cousins were as depressed and burdened as spouses, parents, and children.

The result of the present study revealed that long period of caregiving every day was associated with higher level of depression among caregivers. Percentage of depression among caregivers who were caring for disabled clients for four hours or more per day was higher than those who were caring for their clients less than four hours per day. This result is in consistent with the study of (Washio et al., 2014) which showed that the spending more hours in caring of disabled clients was associated with higher percentage of depression among caregivers. This can be explained that spending longtime in caring or doing same duties routinely and necessarily every day is logically 
leading to depression. More time spent by the caregiver may be a risk factor for stress, caregivers is heavily stressed when spending more time for caring for older people, with mental and physical disability.

The present study showed that the duration of caregiving ( $>6$ months) is significantly correlated to caregiver depression and is a predictor of caregiver burden. This is consistent with the findings of a study that was carried out on caregivers of Alzheimer's dementia patients (García-Alberca et al., 2011). This may be because of the nature of organ failure patients and the unexpected fluctuating course of disease, which places more burden on caregivers.

However, a study by Razali et al. (2011) shows that caregiver's depression is not significantly related to the duration of caregiving. In contrast, McConaghy and Caltabiano (2005), found that caring for a patient with dementia over a long period of time was associated with decreased levels of caregiver's depression and increased well-being. In the current study, the mean score of burden of care level among caregivers of clients diagnosed with mental disability was higher than caregivers of clients diagnosed with physical disability (18.84 and 18.62 respectively), as indicated in Table 3. In addition, the mean score of depression among caregivers of clients diagnosed with mental disability was higher than caregivers of clients diagnosed with physical disability (17.43 and 17.03 respectively), as indicated in Table 4. Moreover, there was no significant difference in depression level and burden of care as regard to nature of relative illness $(p<0.05)$. This finding agreed with Scultz \& Martire (2004) who stated that caregivers of an older people. With psychological illness such as dementia were associated with higher levels of mental health problems compared to caregivers of a relative with a physical illness. This can be explained that most patients with mental disabilities have been living in close contact with their families, which have often represented the primary resource for their social integration. Fluctuation of symptoms is more prevalent among mentally disabled clients creating additional source of burden and depression among their caregivers. Numerous studies have demonstrated that family caregivers of clients with severe mental illness suffer from significant stresses, experience moderately high levels of burden, and often receive inadequate assistance from mental health professionals. For families who are already confronted with a range of day-to-day problems that affect all aspects of their lives, a member with a severe mental illness may have a significant impact on the entire family system (Saunders, 2003). The main limitation of the study is that small sample size and participants were recruited from one site which jeopardies the generalizability of the study findings.

\section{Conclusion and Recommendation}

The study concluded that providing are for clients diagnosed with mental disability posits higher level of burden on family caregivers compared with caregivers of clients diagnosed with physical disability. This negative consequence was linked with high level of depression among those caregivers. As a result, the main recommendation based on the study findings is

1) Implementation of programs in each healthcare unit to educate caregivers how to deal with care stressors and their negative effects as well as enhance caregivers' abilities regarding coping strategies and problem solving.

2) There is a need to adopt effective strategy to lower burden of caregiving and to prevent adverse outcomes for disabled clients and their caregivers.

\section{Authors' Contributions}

The authors had equal contribution into the manuscript

AAH Design the study

AAH Collected data

AAH - Analyse and Report the Result

\section{Ethics Approval and Consent to Participate}

Ethical approval was obtained from FCMS and from all the study participants

\section{Consent to Publish}

"Not applicable" in this section as no personal information is provided in your manuscript.

\section{Availability of Data and Materials}

The datasets used and/or analyzed during the current study are available from the corresponding author on reasonable request

\section{Funding}

The authors thank FCMS for its fund. 


\section{Acknowledgements}

We thank all the study participants for their contribution.

\section{Competing Interests Statement}

The authors declare that there are no competing or potential conflicts of interest.

\section{References}

Arai, Y., Kumamoto, K., Mizuno, Y., \& Washio, M. (2014). Depression among family caregivers of community-dwelling older people who used services under the Long Term Care Insurance program: a large-scale population-based study in Japan. Aging \& mental health, 18(1), 81-91. https://doi.org/10.1080/13607863.2013.787045

Braithwaite, V. (1996). Understanding stress in informal caregiving: Is burden a problem of the individual or of society? Research on Aging, 18, 139-174. https://doi.org/10.1177/0164027596182001

Cohen, C. A., Colantonio, A., \& Vernich, L. (2002). Positive aspects of caregiving: rounding out the caregiving experience. Int J Geriatr Psychiatry, 12, 184-188. https://doi.org/10.1002/gps.561

Ellenbecker, C. H., Porell, F. W., Samia, L., Byleckie, J. J., \& Milburn, M. (2008). Predictors of home healthcare nurse retention. Journal of Nursing Scholarship, 40(2), 151-160. https://doi.org/10.1111/j.1547-5069.2008.00220.x

Eri, H., Masakazu, W., Yumiko, A., Ryuji, S., Mitsuru, M., \& Toshikazu, S. (2013). Depression among Family Caregivers of Patients with Dementia Attending to Psychiatric Dispensary in Northern Japan. International Medical Journal, 20(1), 9-12.

García-Alberca, J. M., Lara, J. P., \& Berthier, M. L. (2011). Anxiety and depression in caregivers are associated with patient and caregiver characteristics in Alzheimer's disease. Int $J$ Psychiatry Med, 41, 57-69. https://doi.org/10.2190/PM.41.1.f

Given, B., Wyatt, G., Given, C., Gift, A., Sherwood, P., DeVoss, D., \& Rahbar, M. (2004, November). Burden and depression among caregivers of patients with cancer at the end-of-life. In Oncology nursing forum (Vol. 31, No. 6, p. 1105). NIH Public Access. https://doi.org/10.1188/04.ONF.1105-1117

Gray, A. J., Ezzat, A., \& Volker, S. (1995). Developing palliative care services for terminally ill patients in Saudi Arabia. Annals of Saudi medicine, 15(4), 370-377. https://doi.org/10.5144/0256-4947.1995.370

Hussain, I. A. (2015). Population aging in Saudi Arabia. Saudi Arabian Monetary Agency, 15(2), 3-9.

Khan et al. (2016). Burden and Depression among Caregivers of Visually Impaired Patients in a Canadian Population. Adv Med, 46, 83-85. https://doi.org/10.1155/2016/4683427

Khare, et al. (2016). Burden and depression in primary caregivers of persons with visual impairment. Indian $J$ Ophthalmol, 64(8), 572-577. https://doi.org/10.4103/0301-4738.191493

Koh, S. K., \& MacDonald, M. (2006). Financial reciprocity and elder care: Interdependent resource transfers. Journal of Family and Economic, 27, 420-436. https://doi.org/10.1007/s10834-006-9028-5

Lou, Q., Liu, S., Huo, Y. R., Liu, M., Liu, S., \& Ji, Y. (2015). Comprehensive analysis of patient and caregiver predictors for caregiver burden, anxiety and depression in Alzheimer's disease. Journal of Clinical Nursing, 24(17/18), 2668-2678. https://doi.org/10.1111/jocn.12870

Mc Grath, E., Puryear Keita, G., Stricland, B. R., \& Felipe Russo, N. (1992). Women and Depression: Risk Factors and Treatment Issues. American Psychological Association, Washington, DC.

McConaghy, R., \& Caltabiano, M. L. (2005). Caring for a person with dementia: exploring relationships between perceived burden, depression, coping and well-being. Nurs Health Sci, 7, 81-91. https://doi.org/10.1111/j.1442-2018.2005.00213.x

Miles, M. B., \& Huberman, M. (1994). Qualitative Data Analysis: A Sourcebook of New Methods. Beverly Hills, CA: Sage Publications; 1994.

Mosqueda, L., Burnight, K., Liao, S., \& Kemp, B. (2004). Advancing the field of elder mistreatment: A new model for integration of social and medical services. The Gerontologist, 44(5), 703-708. https://doi.org/10.1093/geront/44.5.703

National Alliance for Caregiving (NAC), and AARP. (1997, 2004, 2008, 2009, 2012). Caregiving in the U.S. Washington, DC. 
Onwuegbuzie, A. J., \& Collins, K. M. T. (2007). A Typology of Mixed Methods Sampling Designs in Social Science Research. Qualitative Report, 12, 281-316.

Osaki, T., Morikawa, T., Kajita, H., Kobayashi, N., Kondo, K., \& Maeda, K. (2016). Caregiver burden and fatigue in caregivers of people with dementia: Measuring human herpesvirus (HHV)-6 and-7 DNA levels in saliva. Archives of gerontology and geriatrics, 66, 42-48.

Ostman \& Hanssob (2002). Children in families with a severely mentally ill member. Prevalence and needs for support. Soc Psychiatry Psychiatr. Epidemiol, 37(5), 243-8. https://doi.org/10.1007/s00127-002-0540-0

Oura et al. (2007). Depression among caregivers of the frail older people. in Japan before and after the introduction of the Public Long-Term Care Insurance System. $Z$ Gerontol Geriatr, 40, 112-118. https://doi.org/10.1007/s00391-007-0412-z

Pakenham, K. I. (2001). Application of a stress and coping model to caregiving in multiple sclerosis. Psychology, Health \& Medicine, 6, 13-27. https://doi.org/10.1080/13548500125141

Park, B., Kim, S. Y., Shin, J., Sanson-Fisher, R. W., Shin, D. W., Cho, J., \& Park, J. (2013). Prevalence and predictors of anxiety and depression among family caregivers of cancer patients: a nationwide survey of patient-family caregiver dyads in Korea. Supportive Care In Cancer: Official Journal Of The Multinational Association Of Supportive Care In Cancer, 21(10), 52-61. https://doi.org/10.1007/s00520-013-1852-1

Pinquart, M. \& Sorenson, S. (2005). Ethnic Differences in Stressors, Resources, and Psychological Outcomes of Family Caregiving: A Meta-Analysis. The Gerontologist, 45, 90-106. https://doi.org/10.1093/geront/45.1.90

Pirraglia, P. A., Bishop, D., Herman, D. S., Trisvan, E., Lopez, R. A., Torgersen, C. S., ... \& Stein, M. D. (2005). Caregiver burden and depression among informal caregivers of HIV-infected individuals. Journal of general internal medicine, 20(6), 510-514. https://doi.org/10.1111/j.1525-1497.2005.0073.x

Polenick and Martire (2013). Caregiver Attributions for Late-Life Depression and Their Associations with Caregiver Burden. Fam Process, 52(4), 709-722. https://doi.org/10.1111/famp.12032

Razali, R., Ahmad, F., Rahman, F. N. A., Midin, M., \& Sidi, H. (2011). Burden of care among caregivers of patients with Parkinson disease: a cross-sectional study. Clin Neurol Neurosurg, 113, 639-643. https://doi.org/10.1016/j.clineuro.2011.05.008

Saunders, M. M. (2003). Factors associated with caregiver burden in heart failure family caregivers. West $J$ Nurs Res, 30, 943-959. https://doi.org/10.1177/0193945908319990

Schulz, R., O'Brien, A., Czaja, S., Ory, M., Norris, R., Martire, L. M., ... \& Burns, R. (2002). Dementia caregiver intervention research: in search of clinical significance. The Gerontologist, 42(5), 589-602. https://doi.org/10.1093/geront/42.5.589

Stolley, J. M., Reed, D., \& Buckwalter, K. C. (2002). Caregiving appraisal and interventions based on the progressively lowered stress threshold model. American Journal of Alzheimer's Disease \& Other Dementias, 17, 110-120. https://doi.org/10.1177/153331750201700211

Toyoshima, Y., Washio, M., Ishibashi, Y., Onizuka, J., Miyabayashi, I., \& Arai, Y. (2012). Burden among Family Caregivers of the Psychiatric Patients with Visiting Nursing Services in Japan. International Medical Journal, 19(2), 463-465.

Vitaliano, P., Russo, J., Young, H., Teri, L., \& Maiuro, R. (2003). Predictors of burden in spouse caregivers of individuals with Alzheimer's disease. Psychology and Aging, 6(3), 392-402. https://doi.org/10.1037/0882-7974.6.3.392

Wang, L. J., Zhong, W. X., Ji, X. D., \& Chen, J. (2016). Depression, caregiver burden and social support among caregivers of retinoblastoma patients in China. International journal of nursing practice, 22(5), 478-485. https://doi.org/10.1111/ijn.12458

Washio et al. (2015). Depression among caregivers of the frail older people: Three years after the introduction of public long-term care insurance for the older people. Int Med J, 10, 179-183.

Washio, M., Takeida, K., Arai, Y., Shang, E., Oura, A., \& Mori, M. (2015). Depression among Family Caregivers of the Frail Elderly with Visiting Nursing Services in the Northernmost City of Japan. International Medical Journal, 22(4), 250- 253.

World Health Organization [WHO]. (2016). Multisectoral action for a life course approach to healthy ageing: draft global strategy and plan of action on ageing and health. 69th World Health Assembly, Geneva, 2016 April 22 
(A69/17). Retrieved from http://apps.who.int/gb/ebwha/pdf_files/WHA69/A69_17-en.pdf

Yasuko, T., Masakazu, W., Ikuko, M., Shigemi, H., \& Yumiko, A. (2014). PSYCHOLOGICAL MEDICINE. Depression among Family Caregivers of the Psychiatric Patients with Visiting Nursing Services in Japan. International Medical Journal, 21(5), 463-465.

\section{Copyrights}

Copyright for this article is retained by the author(s), with first publication rights granted to the journal.

This is an open-access article distributed under the terms and conditions of the Creative Commons Attribution license (http://creativecommons.org/licenses/by/4.0/). 